Cyttaria hariotii E.Fisch. as a promising source of pullulan and Mn(II)pullulan complexes for Mn-deficiency remediation in winter cereals

M. C. Ramos-Sánchez ${ }^{\mathrm{a}}$, J. Martín-Gilib , L. Buzón-Durán ${ }^{\mathrm{b}}$ and P. Martín$\operatorname{Ramos}^{\mathrm{c}^{*}}$

${ }^{a}$ Servicio de Microbiología. Hospital Universitario Rio Hortega. Calle Dulzaina, 2, 47012 Valladolid, Spain; ${ }^{b}$ Agriculture and Forestry Engineering Department, ETSIIAA, Universidad de Valladolid, Avenida de Madrid 44, 34004 Palencia, Spain; ${ }^{c}$ EPS, Instituto Universitario de Investigación en Ciencias Ambientales (IUCA), Universidad de Zaragoza, Carretera de Cuarte, s/n, 22071 Huesca, Spain.

* Phone: +34 (974) 292668; Fax: +34 (974) 239302; E-mail: pmr@unizar.es. 


\title{
Cyttaria hariotii E.Fisch. as a promising source of pullulan and Mn(II)- pullulan complexes for Mn-deficiency remediation in winter cereals
}

\author{
Pullulan, a water-soluble polysaccharide consisting of maltotriose units used in \\ the preparation of edible films and in drug delivery, is generally produced from \\ starch by Aureobasidium pullulans (de Bary \& Löwenthal) G.Arnaud fungus. In \\ this article, the characterization of an alternative pullulan source -the stromata of \\ Cyttaria hariotii E.Fisch. fungus- by elemental analysis, infrared spectroscopy \\ and thermal analysis techniques is reported. With a view to a possible \\ valorisation of this pullulan and its derivatives as bioactive formulations in \\ agriculture, low-molecular weight pullulan $(<7 \mathrm{kDa})$ complexes with $\mathrm{Mn}(\mathrm{II})$, \\ suitable for the remediation of Mn-deficiencies in winter cereal by foliar \\ application, were synthesized and characterized by mass spectrometry.
}

Keywords: E1204; FTIR spectroscopy; llao-llao; mass spectrometry; thermal analysis

\section{Introduction}

Cyttaria hariotii E.Fisch. is one of the most common fungi in Andean-Patagonian forests. General information on this fungus is presented in Supplementary Material. The main carbohydrate component of $C$. hariotii is pullulan, an homo-polysaccharide composed by maltotriosyl repeating units and a small number of maltotetraose residues (Shingel 2004). Pullulan is usually biosynthesized by strains of Aureobasidium pullulans (de Bary \& Löwenthal) G.Arnaud, and has applications in blood plasma substitutes, edible coatings for fruits, additives and cosmetics (Piergiovanni and Mascheroni 2007).

Upon subjection to the action of enzymes or by treatments with chemicals, lowmolecular pullulan may be obtained, which can find applications through complexation with divalent transition metal ions (Mitić et al. 2011). Although synthetic procedures for the formation of complexes between $\mathrm{M}(\mathrm{II})$ transition metal ions and pullulan are already 
available in the bibliography (Mitić et al. 2011; Mitić et al. 2018), the one corresponding to $\mathrm{Mn}(\mathrm{II})$-pullulan complexes has not been reported so far.

The aim of the study presented herein has been to investigate the vibrational and thermal properties of $C$. hariotii stromata, assessing its suitability for its potential use as raw material. Given the large number of active centres in pullulan that are capable of bond formation with $\mathrm{M}(\mathrm{II})$ ions, the preparation of $\mathrm{Mn}(\mathrm{II})$ ions complexes with lowmolecular weight pullulan from $C$. hariotii has also been investigated. Such complexes may find application in foliar Mn fertilization.

\section{Results and discussion}

\subsection{Characterization of pullulan from C. hariotii}

\subsubsection{Elemental analysis}

Experimental values of $\mathrm{CHON}$ for $C$. hariotii stromata (36.8\% in $\mathrm{C}, 7.0 \%$ in $\mathrm{H}, 44.5 \%$ in $\mathrm{O}$, and $0.6 \%$ in $\mathrm{N}$ ) were in agreement with calculated values on basis of a $\sim 73 \mathrm{wt} \%$ content in pullulan.

\subsubsection{Vibrational characterization}

The infrared spectra of the samples from $C$. hariotii were compared with those of the commercial pullulan and of maltotriose (Figure S2). Band assignments are summarized in Table S2. The spectra of the samples from $C$. hariotti exhibited very similar features to those of commercial pullulan, although the bands at 720 and $755 \mathrm{~cm}^{-1}$ (maltotetraose units) and at $1080 \mathrm{~cm}^{-1}(\alpha-(1 \rightarrow 4)$ glycosidic linkages $)$ were missing. The absence of bands assignable to ester functionality $\left(1653 \mathrm{~cm}^{-1}\right)$ suggests a low esterification or etherification degree, which confers high solubility. Thus, the concurrence of low 
contents in $\alpha$-(1 $\rightarrow 4)$-D-glucosidic bonds and a low esterification degree would explain the moderate-high solubility in water exhibited by pullulan from C. hariotii.

\subsubsection{Thermal characterization}

The thermal curves of $C$. hariotii stromata samples in inert and oxidative conditions (Figure S3), together with their interpretation, are presented in Supplementary Material. A good correspondence with pullulan obtained from A. pullulans was found for the TG thermograms and the maxima of the DTG peaks and DSC effects (Table S3) (Ramos Sánchez 1990; Katsikas et al. 1993).

\subsubsection{Comparison with pullulan obtained from other sources}

According to both the literature data and results presented above, stromata of $C$. hariotti can be an excellent source of pullulan, although it exhibits differential characteristics as compared to pullulans from other origins, such as its higher water solubility and lower functionalization degree. In addition, while the $\mathrm{Mw}$ of pullulan obtained from $A$. pullulans ranges from thousands to 2,000,000 Da (Rekha and Sharma 2007), pullulan from C. hariotii can have a $\mathrm{M} w$ as low as $140 \mathrm{kDa}$ (Oliva et al. 1986). Moreover, some of the drawbacks detected when A. pullulans is chosen for pullulan production (Mishra 2017) would be avoided.

\subsection{Potential applications of pullulan from $C$. hariotii: complexes of low- molecular weight pullulan with Mn(II)}

As discussed above, low-Mw pullulan can find applications through complexation with divalent transition metal ions (Mitić et al. 2011).

The MALDI-TOF/TOF MS spectra of the Mn(II)-pullulan complexes (Figure S4) showed repeating units of $230 \mathrm{Da}$ and $232 \mathrm{Da}$, which correspond to Glcp(OH) 4 and 
MnGlc $p(\mathrm{OH})$, respectively, where Glcp is the anhydro-glucopyranose moiety. Since peaks with $\mathrm{m} / \mathrm{z}$ difference of $54.9 \mathrm{Da}$ (which would to correspond to $\mathrm{Mn}$ ) did not appear, one may conclude that Mn(II)-RLMP complexes were very stable. According to Mitić et al. (2011), a tentative structure with tetragonal distorted $O_{h}$ coordination with O ligand atoms can be proposed for the $\left[\mathrm{Mn}(\mathrm{Glc} p)_{3}\right]$ and $\left[\mathrm{Mn}_{2}(\mathrm{Glc} p)_{3}\left(\mathrm{H}_{2} \mathrm{O}\right)_{2}\right]$ complexes.

These Mn(II)-pullulan complexes may be useful as a bioactive formulation in agriculture, given that manganese deficiency remains a major unsolved nutritional problem in agricultural plant production. Such deficiency causes substantial yield reductions, especially in the case of winter cereals cultivated on sandy and calcareous soils (Hebbern et al. 2005; Mousavi et al. 2011; Schmidt Sidsel Birkelund et al. 2013), or as a result of increasing phosphorus status due to the application of high levels of animal manure and P-fertilizers (Schjoerring et al. 2011). This deficiency is traditionally corrected by repeated foliar Mn applications (Schmidt Sidsel B. et al. 2016; Ullah et al. 2017). Given the high solubility of the Mn(II)-pullulan complexes reported herein, the pullulan obtained from $C$. hariotti may thus find application in such agricultural practices, using it as a carrier for $\mathrm{Mn}$ (II) delivery and expanding its current applications as a carrier in drug delivery (dos Santos and Grenha 2015; Pandurangan et al. 2016; Nasrollahzadeh et al. 2019).

Alternatively, the pullulan for C. hariotti may also be used for other previously reported applications in agriculture: for instance, as a binding agent for solid fertilizers, providing higher water solubility and allowing time-released $\mathrm{N}$ fertilization (Matsunaga et al. 1977), or in seed coatings (Matsunaga et al. 1978).

\section{Conclusions}

The present study puts forward the use $C$. hariotii as a cheap source of pullulan, using a 
green chemistry technique (sonication) and avoiding some of drawbacks detected when A. pullulans is chosen for pullulan production. Moreover, pullulan from C. hariotii exhibits higher water solubility and a lower functionalization degree than the pullulan obtained from A. pullulans or R. paludigenum, making it more suitable for processing. Whereas hydrophobised pullulan is used preferably as a coating material in drug delivery applications, pullulan with higher water solubility and low viscosity, as the one obtained from $C$. hariotii, may have countless industrial applications as a food additive, blood plasma substitute, flocculant and adhesive. Relative to its potential applications in agriculture, complexes of $\mathrm{Mn}(\mathrm{II})$ ion with low-Mw pullulan $(6 \mathrm{kDa})$ from $C$. hariotii were synthesized and characterized by MALDI TOF/TOF MS. By repeated foliar spraying, these complexes may be suitable for the timely alleviation of latent $\mathrm{Mn}$ deficiency in winter cereals, with a view to ensuring winter survival, and increasing grain yields.

\section{Conflicts of interest}

The authors declare no conflict of interest.

\section{References}

dos Santos MA, Grenha A. 2015. Chapter 7, Polysaccharide nanoparticles for protein and peptide delivery. In: Donev R, editor. Protein and peptide nanoparticles for drug delivery. Amsterdam: Elsevier; p. 223-261.

Hebbern CA, Pedas P, Schjoerring JK, Knudsen L, Husted S. 2005. Genotypic differences in manganese efficiency: field experiments with winter barley (Hordeum vulgare L.). Plant Soil. 272(1-2):233-244.

Katsikas L, Jeremic K, Jovanovic S, Velickovic JS, Popovic IG. 1993. The thermal degradation kinetics of dextran and pullulan. J Therm Anal. 40(2):511-517.

Matsunaga H, Fujimura S, Namioka H, Tsuji K, Watanabe M, inventors; Sumitomo Chemical Company Ltd, assignee. 1977. Fertilizer composition. USA. 
Matsunaga H, Tsuji K, Watanabe M, inventors; Sumitomo Chemical Co Ltd, assignee. 1978. Coated seed containing pullulan-based resin used as binder. USA.

Mishra B. 2017. Major problems addressed in pullulan production: A review. Advances in Biotechnology and Microbiology. 6(5):555696.

Mitić Ž, Cakić M, Nikolić GM, Nikolić R, Nikolić GS, Pavlović R, Santaniello E. 2011. Synthesis, physicochemical and spectroscopic characterization of copper(II)polysaccharide pullulan complexes by UV-vis, ATR-FTIR, and EPR. Carbohydr Res. 346(3):434-441.

Mitić Ž, Nikolić GM, Cakić M, Nikolić GS, Živanović S, Mitić S, Najman S. 2018. Synthesis, spectroscopic and structural characterization of Co(II)-pullulan complexes by UV-Vis, ATR-FTIR, MALDI-TOF/TOF MS and XRD. Carbohydr Polym. 200:25-34.

Mousavi SR, Shahsavari M, Rezaei M. 2011. A general overview on manganese (Mn) importance for crops production. Australian Journal of Basic and Applied Sciences. 5(9):1799-1803.

Nasrollahzadeh M, Sajjadi M, Sajadi SM, Issaabadi Z. 2019. Chapter 5, Green nanotechnology. In: Nasrollahzadeh M, Sajadi M, Atarod M et al., editors. An introduction to green nanotechnology. Amsterdam: Elsevier; p. 145-198.

Oliva EM, Fernandez Cirelli A, de Lederkremer RM. 1986. Characterization of a pullulan in Cyttaria darwinii. Carbohydr Res. 158:262-267.

Pandurangan AK, Kanagesan S, Narayanaswamy R, Mohd. Esa N, Parasuraman P. 2016. Chapter 11, Nanobiomaterial-based delivery of drugs in various cancer therapies. In: Grumezescu AM, editor. Nanobiomaterials in cancer therapy. Oxford: William Andrew-Elsevier; p. 331-365.

Piergiovanni L, Mascheroni E. 2007. Chapter 15, Impiego delle biotecnologie per la produzione di imballaggi per alimenti. In: Gigliotti C, Verga R, editors. Biotecnologie alimentari. Padova, Italy: Piccin Nuova Libraria SpA; p. 323-334.

Ramos Sánchez MdC. 1990. Utilidad del análisis térmico en microbiología. Aplicación de las técnicas TG-DTG, DTA y DSC en la caracterización de polisacáridos de paredes fúngicas. Valladolid, Spain: Universidad de Valladolid.

Rekha M, Sharma CP. 2007. Pullulan as a promising biomaterial for biomedical applications: a perspective. Trends Biomater Artif Organs. 20(2):116-121.

Schjoerring JK, Skytte K, Husted S, Pedas P. 2011. Elevated phosphorus impedes manganese acquisition by barley plants. Frontiers in Plant Science. 2. 
Schmidt SB, Pedas P, Laursen KH, Schjoerring JK, Husted S. 2013. Latent manganese deficiency in barley can be diagnosed and remediated on the basis of chlorophyll a fluorescence measurements. Plant Soil. 372(1-2):417-429.

Schmidt SB, Powikrowska M, Krogholm KS, Naumann-Busch B, Schjoerring JK, Husted S, Jensen PE, Pedas PR. 2016. Photosystem II functionality in barley responds dynamically to changes in leaf manganese status. Frontiers in Plant Science. 7.

Shingel KI. 2004. Current knowledge on biosynthesis, biological activity, and chemical modification of the exopolysaccharide, pullulan. Carbohydr Res. 339(3):447460.

Ullah A, Farooq M, Rehman A, Arshad MS, Shoukat H, Nadeem A, Nawaz A, Wakeel A, Nadeem F. 2017. Manganese nutrition improves the productivity and grain biofortification of bread wheat in alkaline calcareous soil. Exp Agric. 54(5):744754. 
SUPPLEMENTARY MATERIAL

\title{
Cyttaria hariotii E.Fisch. as a promising source of pullulan and Mn(II)- pullulan complexes for Mn-deficiency remediation in winter cereals
}

\author{
M. C. Ramos-Sánchez ${ }^{\mathrm{a}}$, J. Martín-Gil' ${ }^{\mathrm{b}}$ L. Buzón-Durán ${ }^{\mathrm{b}}$ and P. Martín- \\ $\operatorname{Ramos}^{\mathrm{c}^{*}}$
}

a Servicio de Microbiología. Hospital Universitario Rio Hortega. Calle Dulzaina, 2, 47012 Valladolid, Spain; ${ }^{b}$ Agriculture and Forestry Engineering Department, ETSIIAA, Universidad de Valladolid, Avenida de Madrid 44, 34004 Palencia, Spain;

${ }^{c}$ EPS, Instituto Universitario de Investigación en Ciencias Ambientales (IUCA), Universidad de Zaragoza, Carretera de Cuarte, s/n, 22071 Huesca, Spain.

\begin{abstract}
Pullulan, a water-soluble polysaccharide consisting of maltotriose units used in the preparation of edible films and in drug delivery, is generally produced from starch by Aureobasidium pullulans (de Bary \& Löwenthal) G.Arnaud fungus. In this article, the characterization of an alternative pullulan source -the stromata of Cyttaria hariotii E.Fisch. fungus- by elemental analysis, infrared spectroscopy and thermal analysis techniques is reported. With a view to a possible valorization of this pullulan and its derivatives as bioactive formulations in agriculture, low-molecular weight pullulan ( $<7 \mathrm{kDa}$ ) complexes with $\mathrm{Mn}(\mathrm{II})$, suitable for the remediation of Mn-deficiencies in winter cereal by foliar application, were synthesized and characterized by mass spectrometry.
\end{abstract}

Keywords: E1204; FTIR spectroscopy; llao-llao; mass spectrometry; thermal analysis 


\section{General information about Cyttaria hariotii E.Fisch. fungus}

Cyttaria is a genus of ascomycete fungi that encompasses 14 species found in South America and Australia. Among these, the "llao-llao" fungus, Cyttaria hariotii E.Fisch., is one of the most common fungi in Andean-Patagonian forests. Originally described by mycologist M.J. Berkeley in 1842, it owes its name to Greek cyttarion = socket, because of the apothecial cavities of its stroma (Figure S1).

Cyttaria spp. exclusively parasite Nothofagus spp. trees: ‘ñire’ (Nothofagus antarctica (G.Forst.) Oerst.), 'lenga’ (Nothofagus pumilio Krasser), ‘coihue’ or 'coigüe’ (Nothofagus dombeyi (Mirb.) Oerst.), 'guindo' (Nothofagus betuloides (Mirb.) Oerst.) and ‘coihue’ or ‘coigüe de Magallanes’ (Nothofagus nitida Krasser).

Cyttaria fructifications (stromata) form annually in spring and can reach the size of golf ball (Figure S1). In particular, the fruiting bodies of $C$. hariotii typically have a distinctive yellow to orange colour and were used by indigenous people of the region (the mapuches) for the production of an alcoholic drink ('chicha').
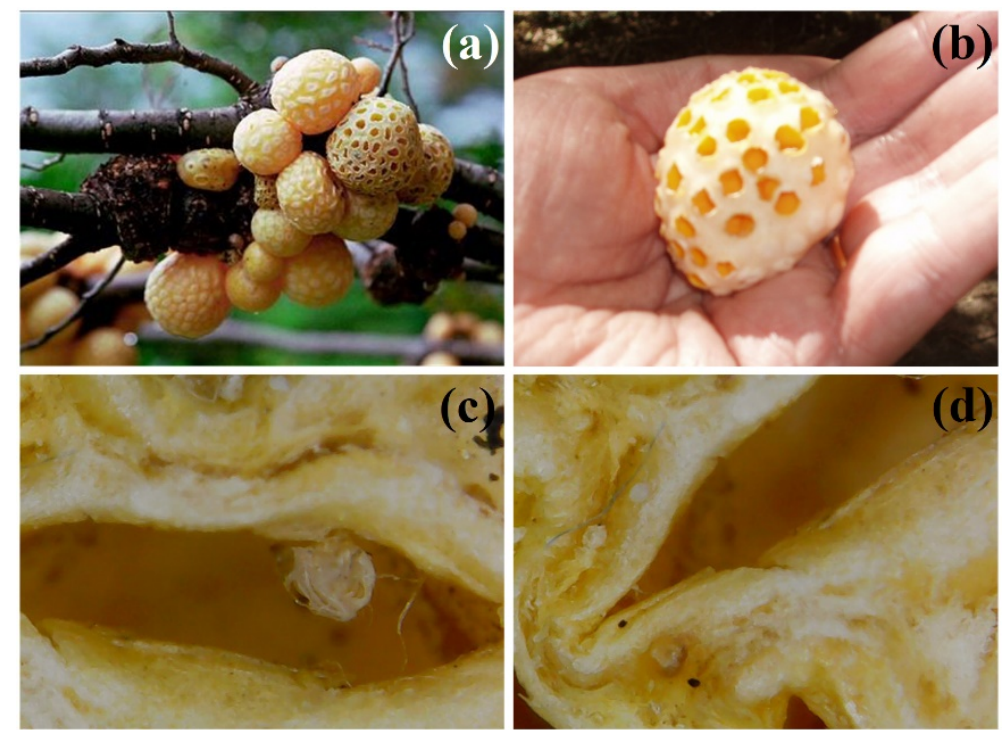

Figure S1. Stromata of Cyttaria hariotii showing the immersed apothecia: (a,b) photos, and (c,d) micrographs at 500× magnification. 
Previously reported analyses of Cyttaria spp. showed that their crude lipid and ash contents were similar to those of other edible fungi, but amino acid analyses revealed that proteins were deficient in methionine and cysteine, and that the contents in valine, isoleucine, leucine, and lysine amino acids were below the WHO recommended values (Schmeda-Hirschmann et al. 1999). As regards their carbohydrate content, Cyttaria spp., when mature, show up to $10 \% \mathrm{w} / \mathrm{v}$ of simple sugars (Lederkremer and Ranalli 1967) and up to 73\% of polysaccharides. Other bromatological analysis results for C. hariotii are reported in Table S1.

Table S1. Bromatological analysis of Cyttaria hariotii collected from Fuerte de Bulnes, Chile (expressed in g per 100 g of dry weight) (Schmeda-Hirschmann et al. 1999).

\begin{tabular}{cccccccc}
\hline Sample & Moisture & $\begin{array}{c}\text { Crude } \\
\text { protein }\end{array}$ & $\begin{array}{c}\text { Crude } \\
\text { lipids }\end{array}$ & $\begin{array}{c}\text { Crude } \\
\text { fiber }\end{array}$ & Ash & NNE & $\begin{array}{c}\text { Phosphate } \\
\text { (mg\%) }\end{array}$ \\
\hline Cyttaria hariotii & 10.0 & 7.50 & 2.10 & 8.00 & 7.00 & 75.40 & 100.0 \\
\hline
\end{tabular}

NNE: non-nitrogenated elements (carbohydrates).

\section{Pullulan: structural information, properties and obtaining methods}

Pullulan is an extracellular homo-polysaccharide composed by maltotriosyl repeating units $(\alpha-(1 \rightarrow 4)$ Glcp- $\alpha-(1 \rightarrow 4)$ Glcp- $\alpha-(1 \rightarrow 6)$ Glcp- $)$, connected by $\alpha-(1 \rightarrow 6)$ linkages of linear $\alpha-(1 \rightarrow 6)$ linked maltotriose units and a small number of randomly distributed maltotetraose $(\alpha-(1 \rightarrow 4)$ Glcp- $\alpha-(1 \rightarrow 4)$ Glcp- $\alpha-(1 \rightarrow 4)$ Glcp- $\alpha-(1 \rightarrow 6)$ Glcp-) residues (Shingel 2004) (Glcp=D-glucopyranose). Despite its linear structure, it exhibits good flexibility. The $\alpha-(1 \rightarrow 6)$ linked maltotriose repeat unit interferes with hydrogen bonding and crystallization, and confers higher water solubility on pullulan (unlike cellulose and other well-known polysaccharides). Another characteristic of pullulan associated with its solubility is its esterification or etherification degree: it is known that partial esterification or etherification of the polymer chain can reduce its solubility in water and that a complete esterification or etherification results in insolubility (Yuen 1974). 
Important properties of pullulan are its high resistance to fats, its ability to act as good barrier to gases and being non-toxic, biodegradable, non-mutagenic and noncarcinogenic.

Pullulan is usually biosynthesized by strains of the yeast-like polymorphic fungus Aureobasidium pullulans (de Bary \& Löwenthal) G.Arnaud, and is more expensive (ca. $25 \$ / \mathrm{kg}$ ) than other exopolysaccharides, which is a major limiting factor for its effective application. The high production costs for pullulan production by $A$. pullulans may be reduced by the alternative use of other potential sources: the saprophytic (sometimes mycoparasitic) fungus Tremella mesenterica Retz. (Fraser and Jennings 1971); the fungal agent of chestnut blight, Cryphonectria parasitica (Murrill) M.E.Barr (Corsaro 1998); the obligate tree parasitic fungi C. hariotii and Cyttaria darwinii Berk. (Oliva, Cirelli, et al. 1986; Oliva, Fernandez Cirelli, et al. 1986); the lichenized ascomycete Teloschistes flavicans (Sw.) Norman (Reis 2002); Rhodotorula bacarum (Buhagiar) Rodr.Mir. \& Weijman (Chi and Zhao 2003) and, recently, Rhodosporidium paludigenum Fell \& Tallman (Singh and Kaur 2018).

\section{Experimental}

The samples of "llao-llao" (C. hariotii) under study were collected in the Bernardo O'Higgins National Park ( $\left.50^{\circ} \mathrm{S}, 74^{\circ} \mathrm{W}\right)$, Chile, in December 2018. The identification was based on morphological data and host associations.

Standard pullulan from A. pullulans (CAS 9057-02-7) was purchased from Sigma-Aldrich (Merck KGaA, Darmstadt, Germany) for comparison purposes. Maltotriose (CAS 1109-28-0; $\geq 90 \%$ ), also used for comparison purposes, was supplied by Henan DaKen Chemical Co. Ltd. (Zhengzhou City, China). 
Pullulan from C. hariotii was extracted from "llao-llao" stromata by ultrasonic assisted digestion in water (200 mg/10 mL) for 2 hours. A UIP1000hdT (Hielscher, Teltow, Germany, $1000 \mathrm{~W}, 20 \mathrm{kHz}$ ) ultrasonic bath was used to promote the extraction of pullulan. The ultrasound bath equipment was filled with water and a one-by-time glass centrifuge tube was placed, with the aid of a base, in the centre of the bath to perform the ultrasound-assisted extraction. A Labolan (Esparza de Galar, Navarra, Spain) centrifuge with $50 \mathrm{~mL}$ centrifuge tubes was used to separate the solid from the liquid phase.

Hydrolysis of pullulan from C. hariotii was carried out by addition of citric acid (CAS 77-92-9, $\geq 99.5 \%$ ) and hydrogen peroxide (CAS 7722-84-1, 30 wt.\% in $\mathrm{H}_{2} \mathrm{O}$ ), purchased from Sigma-Aldrich. Optional release of protein remains from the C. hariotii hydrogel was attained by adding $1 \mathrm{~mL}$ of $10 \% \mathrm{v} / \mathrm{v}$ Neutrase ${ }^{\circledR}$ (E.C.3.4.24), a zinc metallo endo-protease from Bacillus amyloliquefaciens that randomly hydrolyses peptide bonds, supplied by Strem Chemicals Inc. (Newburyport, MA, USA).

Manganese(II)-pullulan complexes were synthesized at neutral or slightly alkaline $\mathrm{pH}$ from pullulans of certain MW produced by partial hydrolysis of $C$. hariotii pullulan with citric acid, successive fractionation with $96 \%$ (vol.) ethanol, subsequent alkalinisation with $\mathrm{NaOH}$ and finally, by dropwise addition of $100 \mathrm{mM} \mathrm{MnCl}$.

Optical microscopy images were acquired with an Avangard Optics (China) AN-E500 iScope 500x USB digital microscope.

Carbon/Hydrogen/Nitrogen (CHN) elemental analysis was carried out with a LECO (St. Joseph, MI, USA) CNH628 apparatus. A non-dispersive infrared absorption system was used for detection of $\mathrm{C}$ and $\mathrm{H}$, and a thermal conductivity (TC Cell) system was used for detection of $\mathrm{N}$. 
The infrared vibrational spectrum was characterized using a Thermo Scientific (Waltham, MA, USA) Nicolet iS50 Fourier-Transform Infrared (FTIR) spectrometer, equipped with an in-built diamond attenuated total reflection (ATR) system. The spectrum was collected in the 400-4000 $\mathrm{cm}^{-1}$ region at room temperature, with a $1 \mathrm{~cm}^{-1}$ spectral resolution; a total of 64 scans were co-added and the resulting interferogram was averaged.

Thermal analysis was performed with a Mettler Toledo (Columbus, OH, USA) TG-DSC2 device, heating the samples from 50 to $600{ }^{\circ} \mathrm{C}$, under both $\mathrm{N}_{2}$ and air flow $\left(20 \mathrm{~cm}^{3} \cdot \mathrm{min}^{-1}\right)$, with a heating rate of $20^{\circ} \mathrm{C} \cdot \mathrm{min}^{-1}$.

MALDI-TOF/TOF MS characterization was performed using the "dried droplet" method to prepare the samples. $2.0 \mu \mathrm{L}$ of matrix $(10 \mathrm{mg} / \mathrm{mL}$ 2,5-dihydroxybenzoic acid, DHB) and $2.0 \mu \mathrm{L}$ of pullulan complex $(1 \mathrm{mg} / \mathrm{mL})$ were mixed, and then $0.5 \mu \mathrm{L}$ of the obtained mixture was applied on a MALDI target plate of polished steel (Bruker Daltonik GmbH, Bremen, Germany) and allowed to dry for 15 min at room temperature. The plate was inserted into a Bruker Autoflex LRF speed mass spectrometer operating in linear positive mode in the $\mathrm{m} / \mathrm{z}$ range of $450-10000 \mathrm{Da}$. A solid-state, Nd:YAG 355 run SmartBeam laser, with a frequency of $1000 \mathrm{~Hz}$ was used for ionization. Spectra were obtained by accumulating 2000 laser shots from 4 different spots. The MS spectra were acquired using the FlexControl software.

\section{Vibrational characterisation results}

The infrared spectra of the samples from $C$. hariotii and of the commercial pullulan used as a reference are compared in Figure S2 and Table S2. The strong absorption at $3300 \mathrm{~cm}^{-1}$ indicates that both Cyttaria-derived samples and commercial pullulan have some $-\mathrm{OH}$ repeating units. The other strong absorption bands at $2920 \mathrm{~cm}^{-1}$ and 2849 
$\mathrm{cm}^{-1}$ indicate that a sp ${ }^{3} \mathrm{C}-\mathrm{H}$ bond of alkane compounds exists. The band at $1683 \mathrm{~cm}^{-1}$ may result from chelation between a $\mathrm{C}=\mathrm{O}$ group and a neighbouring $\mathrm{O}-\mathrm{H}$ group. In the $1560-650 \mathrm{~cm}^{-1}$ region, which is characteristic for the pullulan molecule as a whole, the spectra of the samples from $C$. hariotti exhibited very similar features to those of commercial pullulan. The absorption at around $1558 \mathrm{~cm}^{-1}$ represents $\mathrm{C}=\mathrm{C}$ stretching vibration indicative of the lignin. Absorption bands at 1638, 1370 and $1150 \mathrm{~cm}^{-1}$ should be assigned to $\mathrm{O}-\mathrm{C}-\mathrm{O}$ stretching, $\mathrm{C}-\mathrm{O}-\mathrm{H}$ bending and $\mathrm{C}-\mathrm{O}-\mathrm{C}$ stretching, respectively.

Absorption at $920 \mathrm{~cm}^{-1}$ is indicative of the presence of $\alpha-(1 \rightarrow 6)$-D-glucosidic bonds, while the absorptions at 755 and $720 \mathrm{~cm}^{-1}$ are associated with the presence of $\alpha$ $\left(1 \rightarrow 4\right.$ )-D-glucosidic bonds (Thirumavalavan et al. 2009). The weak band at $835 \mathrm{~cm}^{-1}$ is also associated with $\alpha$-D-glucopyranoside units.

Absorptions intensities at 1080 and $1105 \mathrm{~cm}^{-1}$ inform on the proportion of $\alpha$ $(1 \rightarrow 6)$ and $\alpha-(1 \rightarrow 4)$ glycosidic linkages in the pullulan chains. The disappearance or a decrease in intensity of the band at $1080 \mathrm{~cm}^{-1}$ in favour of the one that appears at 1105 $\mathrm{cm}^{-1}$ implies that the $\alpha-(1 \rightarrow 6) / \alpha-(1 \rightarrow 4)$ ratio is higher than that expected from the strict sequence of two $\alpha-(1 \rightarrow 6)$ linkages and one $\alpha-(1 \rightarrow 4)$ in the pullulan structure.

In polysaccharides, when a band appears at $1045 \mathrm{~cm}^{-1}$, it is characteristic of a more organized structure, but when a band at $1020 \mathrm{~cm}^{-1}$ is shown, as it occurs for all the studied samples, an amorphous structure occurs.

In the spectrum of pullulan from C. hariotii treated with Neutrase ${ }^{\circledR}$ for purification purposes, a strong absorption band at $1148 \mathrm{~cm}^{-1}$ (C-O; $\mathrm{C}-\mathrm{C}$ stretching) was observed, together with the absence of the bands at $1636 \mathrm{~cm}^{-1}$ and at $1420-1436 \mathrm{~cm}^{-1}$ $\left(\mathrm{COO}^{-}\right.$stretching vibration, attributed of carboxyl groups) (Nejatzadeh-Barandozi and Enferadi 2012), and at $1254 \mathrm{~cm}^{-1}$. Since carboxyl constitutes the main functional moiety 
involves in flocculation (Zheng et al. 2008; Wan et al. 2013), its entire removal from pullulan would not be positive, advising against the use of this treatment.

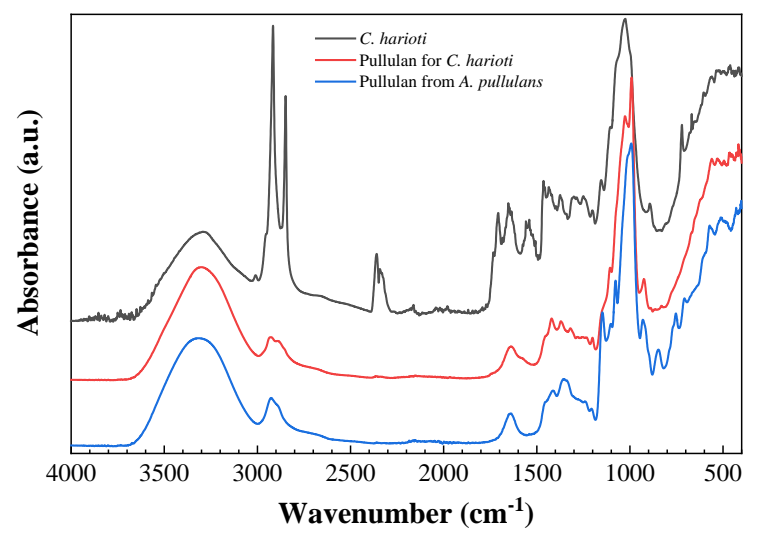

Figure S2. FTIR spectra of Cyttaria hariotii, pullulan obtained from C. hariotii and pullulan obtained from A. pullulans.

Table S2. Comparison of the absorption bands in the FTIR spectra of "llao-llao"

(Cyttaria hariotii) fungus, of its main component, of commercial pullulan obtained from A. pullulans and of maltotriose.

\begin{tabular}{|c|c|c|c|c|c|}
\hline \multirow{2}{*}{ C. hariotii } & \multicolumn{3}{|c|}{ Pullulan from } & \multirow{2}{*}{ Maltotriose } & \multirow{2}{*}{ Assignation } \\
\hline & C. hariotii & C. hariotii $^{\dagger}$ & A. pullulans & & \\
\hline 3291 & 3300 & 3351 & 3312 & & OH stretching vibrations \\
\hline 3010 & & & & & intrahydrogen bonds \\
\hline 2916 & 2927 & 2938 & 2926 & 2926 & C-H stretch \\
\hline 2849 & & & & & C-H stretch \\
\hline 2360 & & & & & C-O stretch (carboxylic group) \\
\hline 1733 & & & & & $\mathrm{C}=\mathrm{O}$ stretch (o-acetyl esters) \\
\hline 1707 & & 1712 & & & $\mathrm{C}=\mathrm{O}($ carboxyl $)$ \\
\hline 1684 & & & & & $\mathrm{C}=\mathrm{O}$ and $\mathrm{O}-\mathrm{H}$ chelation $/$ amide $\mathrm{I}$ \\
\hline 1653 & & & 1654 & & C-O stretch (esters) \\
\hline 1647 & & & 1645 & & $\mathrm{O}-\mathrm{H}$ bending / $\mathrm{O}-\mathrm{C}-\mathrm{O}$ \\
\hline 1636 & 1636 & & 1637 & 1637 & asymmetrical $\mathrm{COO}^{-}$stretch \\
\hline 1558 & & & & & $\mathrm{C}=\mathrm{C}$ stretch $/ \mathrm{COO}^{-}$, amide II \\
\hline 1540 & & & & & -NH deformation \\
\hline 1507 & & & & & $\mathrm{C}=\mathrm{C}$ aromatic \\
\hline 1464 & & & 1454 & & $\mathrm{C}-\mathrm{H}$ stretch / C-O stretch and $\mathrm{O}-\mathrm{H}$ bend \\
\hline 1436 & 1420 & & 1423 & 1416 & $\mathrm{C}-\mathrm{O}-\mathrm{H}$ bend / $\mathrm{C}=\mathrm{O}$ str $(\mathrm{sym})$ of $\mathrm{COO}^{-}$ \\
\hline 1375 & 1371 & 1397 & $1355-68$ & 1367 & $\mathrm{C}-\mathrm{O}-\mathrm{H}$ bend / S-O stretch \\
\hline 1301 & 1320 & 1332 & & & $\mathrm{CH}_{2}$ twisting \\
\hline 1250 & 1254 & & $1250-56$ & 1255 & $\omega$-carboxyalkanoates / o-acetyl esters \\
\hline 1201 & 1201 & 1202 & 1206 & 1201 & $\mathrm{C}-\mathrm{O}-\mathrm{C}$ stretch in esters \\
\hline 1154 & & 1148 & 1158 & 1160 & C-O-C stretch / exocyclic C-O stretch \\
\hline 1104 & 1106 & 1105 & 1077 & & $\mathrm{C}-\mathrm{O}$ stretching / $\mathrm{C}-\mathrm{O}-\mathrm{H}$ bending \\
\hline 1024 & 1027 & 1015 & 1019 & 1029 & $\mathrm{C}-\mathrm{O}$ stretching $/ \mathrm{O}-\mathrm{C}=\mathrm{O}$ \\
\hline & 991 & & 992 & & $\mathrm{CH}_{2}$ twisting \\
\hline 893 & 924 & 896 & 931 & 928 & both $\alpha-(1 \rightarrow 4)$ and $\alpha-(1 \rightarrow 6)$ linkages \\
\hline 837 & 831 & & $832-50$ & 847 & $\alpha$-D-glucopyranoside units \\
\hline & & 773 & 755 & 769 & $\alpha-(1 \rightarrow 4)$ in $(1 \rightarrow 4)(1 \rightarrow 6)$-D-glucans \\
\hline 721 & & & $711-720$ & & $\alpha$-(1 $\rightarrow 4)$-D-glucosidic linkages \\
\hline
\end{tabular}

${ }^{\dagger}$ After Neutrase ${ }^{\circledR}$ treatment 


\section{Thermal characterisation results}

The TG, DTG and DSC curves of $C$. hariotii stromata samples in inert and oxidative conditions are shown in Figure S3.

From the TG curve, at the end of the heating cycle $\left(600^{\circ} \mathrm{C}\right)$ and in $\mathrm{N}_{2}$ atmosphere, about $25.3 \%$ carbonaceous residue was found, a value higher than that obtained in an oxidative atmosphere (16.3\%). For comparison purposes, the heating of commercial pullulan at $650{ }^{\circ} \mathrm{C}$ in $\mathrm{N}_{2}$ has been reported to produce $c a .20 \%$ residue (Katsikas et al. 1993). The difference between the two values should be ascribed to differences both in the final heating temperature and in the heating rates (provided that the formation of char is heating rate dependent, with more residue being produced at lower heating rates).

In DTG curves, two decomposition peaks were observed at around 223.5 and 281-284 ${ }^{\circ} \mathrm{C}$, both in oxidative and non-oxidative conditions (Table S3). These peaks were followed by another five peaks above $440{ }^{\circ} \mathrm{C}$, albeit only in oxidative conditions. While the decomposition under $285{ }^{\circ} \mathrm{C}$ would be representative of long chain scission, the features at higher temperatures would be associated with the decomposition of the glucose ring. For pullulan obtained from A. pullulans, the maxima of the DTG peaks reported by Katsikas et al. (1993) were at 300 and $310^{\circ} \mathrm{C}$, in oxidative and nonoxidative conditions, respectively. However, the authors also referred a small shoulder at about $270{ }^{\circ} \mathrm{C}$ in both the non-oxidative and oxidative case, which was ascribed to the decomposition of lower molecular weight fractions of the sample. The same study also referred that oxidative DTG curves of pullulan had a second maximum at $445^{\circ} \mathrm{C}$. 
Regarding the DSC curves, a good correspondence with the DTG curves was observed, both in oxidative and non-oxidative conditions, for the effects at $\sim 225^{\circ} \mathrm{C}$, at $\sim 275^{\circ} \mathrm{C}$, and the four exotherms that appeared at above $460{ }^{\circ} \mathrm{C}$ (at $461,557,581$ and $590^{\circ} \mathrm{C}$ ). The DSC curves also showed two effects not shown in the DTG curves: one at $178{ }^{\circ} \mathrm{C}$, close to the one exhibited by pullulan obtained from $A$. pullulans at $171.6{ }^{\circ} \mathrm{C}$ (Ramos Sánchez 1990); and another effect at $314-317^{\circ} \mathrm{C}$, in reasonably good correspondence with that exhibited by pullulan at $304.3^{\circ} \mathrm{C}$ in air (at a heating rate of 10 ${ }^{\circ} \mathrm{C} / \mathrm{min}$ ) (Ramos Sánchez 1990).
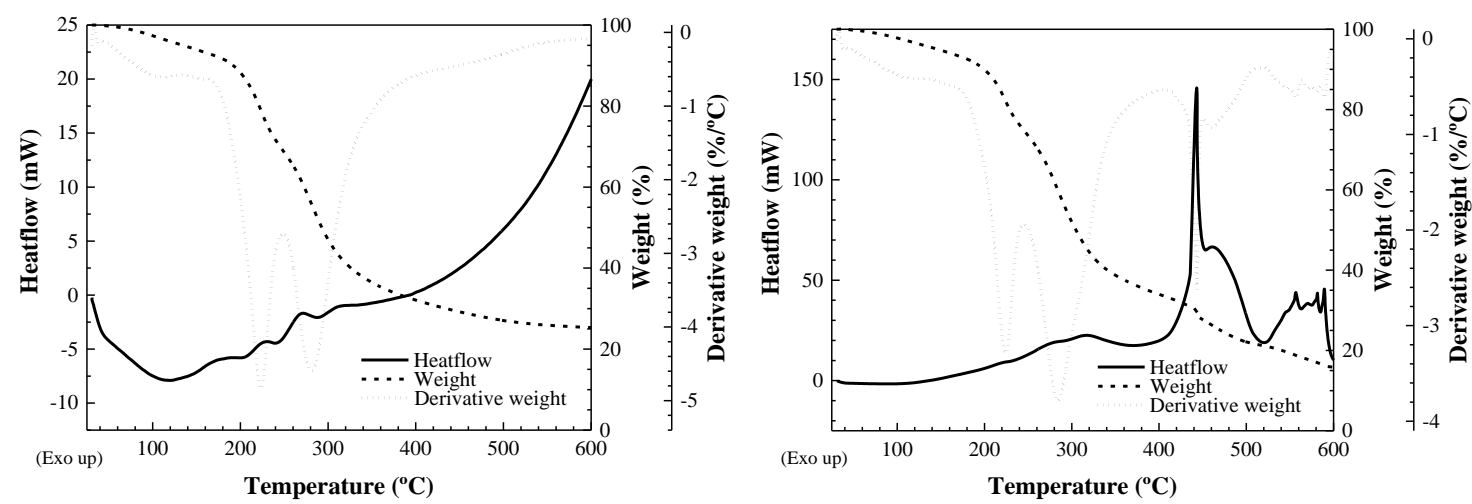

Figure S3. DSC (dotted line, y-axis on the left side of the graph), TG (solid line, first yaxis on the right side of the graph) and DTG (dashed line, second (rightmost) y-axis on the right side of the graph) curves for Cyttaria hariotii stromata in: (left) inert and (right) oxidative conditions.

Table S3. Temperatures of thermal effects for "llao-llao" (Cyttaria hariotii) fungus stromata samples in inert and oxidative conditions.

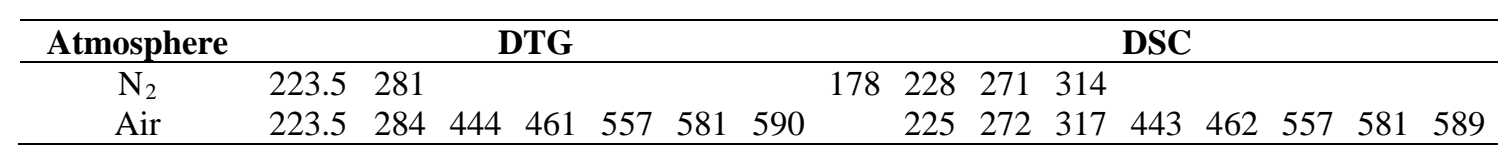

\section{MS characterization of complexes of low-molecular weight pullulan with Mn(II)}

The MALDI-TOF/TOF MS spectra of the Mn(II)-pullulan complexes (Figure S4) showed repeating units of $230 \mathrm{Da}$ and $232 \mathrm{Da}$, which correspond to Glcp(OH) 4 and MnGlcp(OH), respectively, where Glcp is the anhydro-glucopyranose moiety. 
Characteristic peaks were those that occurred at the following $\mathrm{m} / \mathrm{z}: 447.8$

$\left[\mathrm{Mn}_{2}(\mathrm{Glcp})\left(\mathrm{H}_{2} \mathrm{O}\right)_{6}(\mathrm{OH})_{4}\right], 540.4\left[\mathrm{Mn}(\mathrm{Glcp})_{3}\right], 632.3$ [ $\left.\mathrm{Mn}_{2}(\mathrm{Glcp})_{3}\left(\mathrm{H}_{2} \mathrm{O}\right)_{2}\right], 864.7$

$\left[\mathrm{Mn}_{2}(\mathrm{Glcp})_{4}\left(\mathrm{H}_{2} \mathrm{O}\right)_{5}(\mathrm{OH})\right], 1050.0\left[\mathrm{Mn}_{4}(\mathrm{Glcp})_{3}\left(\mathrm{H}_{2} \mathrm{O}\right)_{6}\right]$ and $2224.0\left[\mathrm{Mn}_{11}(\mathrm{Glcp})_{10}\right]$.
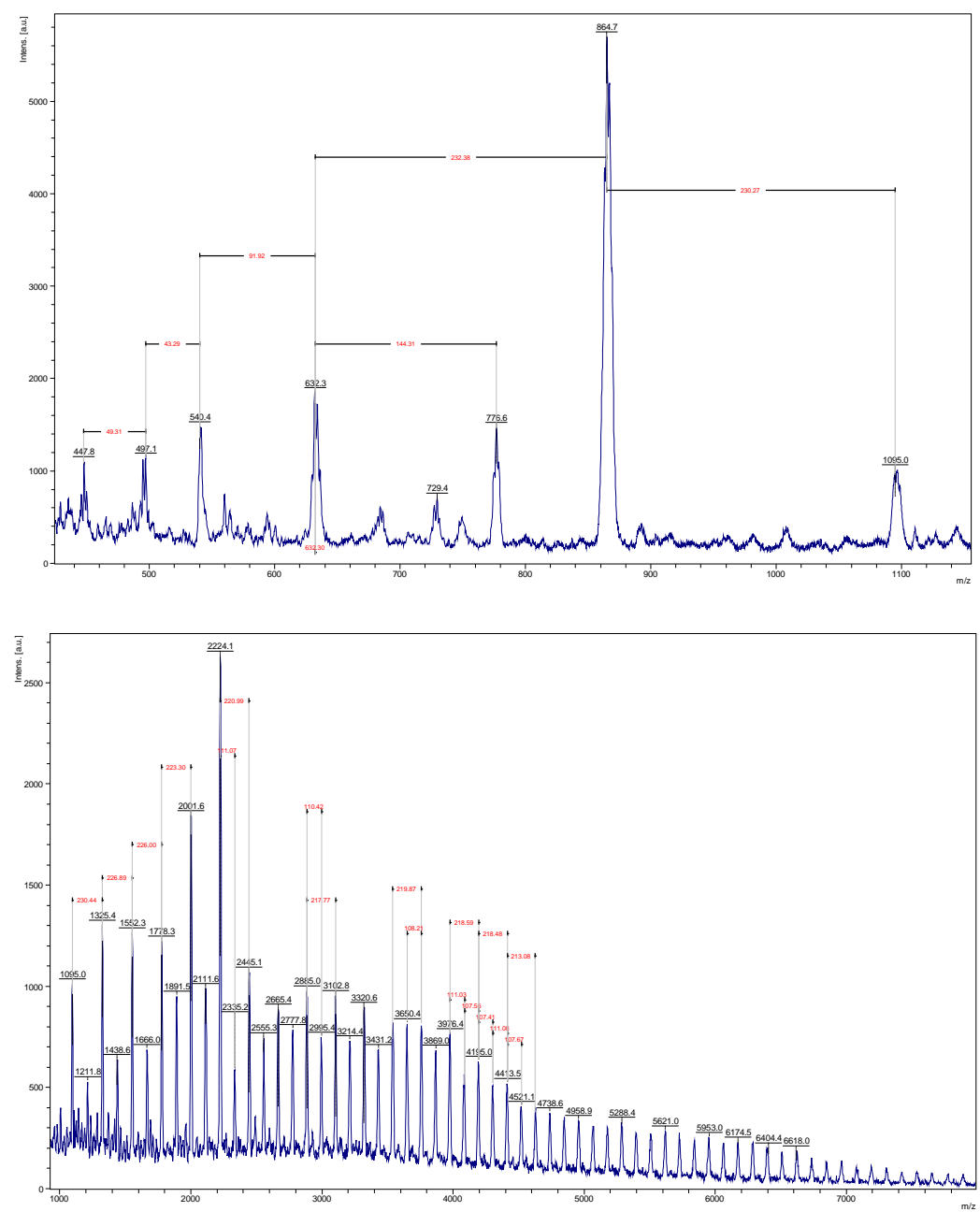

Figure S4. The MALDI-TOF/TOF MS spectra of Mn(II)-low molecular weight pullulan complexes in the 400-1100 Da range (top) and in 1000-7000 Da range (bottom). 